\title{
DESIGN AND ENGINEERING OF THE WORLD'S TALLEST NATURAL DRAUGHT COOLING TOWERS AT 2 × 600 MW KALISINDH THERMAL POWER PROJECT
}

\author{
Patni P. S ${ }^{1}$, Asrondkar J. D ${ }^{2}$ \\ ${ }^{1}$ Joint Vice President, STUP Consultants Pvt. Ltd, Plot 22A, Sector 19C, Palm Beach Marg, Vashi, Navi Mumbai, \\ 400705 Maharashtra, India \\ ${ }^{2}$ Senior Manager (Design), STUP Consultants Pvt. Ltd, Plot 22A, Sector 19C, Palm Beach Marg, Vashi, \\ Navi Mumbai, 400705 Maharashtra, India
}

\begin{abstract}
In the time span of 27 months two natural draught cooling towers (NDCTs) have been built for $2 \times 600$ MW Kalisindh Thermal Power Station at Jhalawar, India with height of $202 \mathrm{~m}$ above the finished ground level (FGL) and $212 \mathrm{~m}$ from founding level. These NDCTs are the tallest cooling towers world-wide. For many reasons, such structures can not be designed merely as enlargement of smaller sizes but they require careful review of the past practices to make sure that the extrapolation of the currently established methods are valid for the increased size. It needs innovative design approach. The paper starts with explanation of functional requirements and description of the tower geometry, followed by elucidation of the structural modeling and special distribution of wind load, both the Codal and the experimental wind load from the wind tunnel tests made on structural model of the towers. Further the structural analysis and design aspects of the towers are described with respect to Indian as well as British codified safety concepts for this structure. Finally, the necessity to improve the durability and measures taken to achieve the same are described.
\end{abstract}

Keywords: NDCT Shell, Wind Load on NDCT, Wind tunnel test

\section{INTRODUCTION}

Thermal power projects can extract only limited amount of energy from the heat generated by burning the fuel in form Electric Power, and the remaining is the waste heat returned to the atmosphere. Water is used for the purpose of taking away the waste heat, to minimise the water demand, Natural Draught Cooling Towers are used as a part of the Cooling Water System (C.W. System), in which the water cooled in the tower returns (re-circulated) to the condenser where the steam from the turbine is condensed to enable further power to be obtained at the low pressure end of the turbine. The cooler the water and greater the quantity, better is the vacuum produced in the condenser and greater the power which can be generated. However, this is at the increased cost of the C.W. System including the cost of NDCTs. Cooling towers, therefore, form an important element in the heat management strategies of the present day environmental controls, improving the sustainability of power production needs of the humanity.

\section{NATURAL DRAUGHT COOLING TOWERS}

With the increasing capacity of power plants in India it has become necessary to increase the cooling capacity of NDCTs, requiring both the additional height and diameter of cooling towers. Traditionally, NDCT consists of main surfaces generated by Shells of revolution about the central vertical axis, with predominantly hyperbolic profile, but also at times using combination of hyperbolic and conical generators. The enclosed space, due to its height and shape creates a natural wind draught which is used to take away heat from the hot water from condensers of the Steam Generating Units trickling down the 'fill' inside the NDCT. The hot water is typically introduced at a height inside the Shell and distributed uniformly over the entire circular plan area through channels/distribution pipes and allowed to trickle down the 'fill', which are specially arranged units of PVC meshes. The 'fill' has certain depth through which the water passes dripping as well as flowing around the surfaces, and cools down in this process, transferring its heat load to the air draught. This is the origin of the name "Natural Draught Cooling Tower". The air enters from the space between ground and the hyperbolic Shell, which is created by supporting the Shell on discrete number of columns, strategically spaced to minimize resistance to the air flow, but transferring the large forces from the Shell to the foundations. The cooled water is collected in the bottom pond and is taken away to become part of the inlet water to the Steam Generating units.

\section{NDCT AT KALISINDH POWER PROJECT}

The large cooling towers being built today are exceptionally large Shell structures being, in proportion, considerably thinner than an eggshell but approaching $202 \mathrm{~m}$ in height. Based on thermal design requirement given by the Thermal designers of Kalisindh NDCT required the following structural configuration: 
Water flow rate: $75000 \mathrm{cum} / \mathrm{hr}$

Total height: $202.00 \mathrm{~m}$ above finished ground level (Tallest in the world)

Throat height: $150.00 \mathrm{~m}$

Height of air inlet: $11.825 \mathrm{~m}$

Basin sill level: $0.00 \mathrm{~m}$

Top diameter: $90.698 \mathrm{~m}$ (Centre Line diameter)

Throat diameter: $87.35 \mathrm{~m}$ (Centre Line diameter)

Basin diameter: $149.350 \mathrm{~m}$ (Centre Line diameter)

\section{STRUCTURAL ELEMENTS OF NDCT}

The general arrangement of the Kalisindh NDCT is shown in fig, 1. The shell is a surface of revolution generated by revolving about the central vertical axis, a composite generator consisting of two hyperbolic curves, one below the throat level and above the throat section and a cone. The RC shell of revolution is supported along the circumference by a system of 60 pairs of RC diagonal columns which are raked tangential to the meridian of the shell at bottom. They are also inclined in plan.

The open system of columns provides the air inlet opening. The diagonal columns rest on $\mathrm{RC}$ pedestals inclined to match the tangent to the meridian of the shell at bottom. RC annular open footing with horizontal base supports the pedestal. RC basin consisting of floor and wall to collect the cooled water. Internal structure comprising arrangement of beam and columns and the basin floor with basin wall are structurally independent from tower shell. The outer shell has $1.5 \mathrm{~m}$ wide peripheral walkway in $\mathrm{RC}$ in channel form at the top which is accessed by two ladders in Galvanised steel starting from the top of RC staircases. The ladders are on the outside of the tower with landing platforms at regular intervals. The RC staircase leads from finished ground levelup to the level of water distribution system.

Design of NDCT tower shell is always a complex and challenging task, inspite of the powerful analytical tool of the Finite Elements Analysis. The Kalisindh NDCTs are in high wind velocity zone $(47 \mathrm{~m} / \mathrm{s}-3$ second gust period) making the design sensitive to wind and therefore complex. For NDCT it is more important to control thicknesses of the shell to keep the quantities and the weight of tower minimum. The thickness to enclosed volume ratio is comparable to an egg shell, which is nature's creation. In Kalisindh, the ratio of thickness to volume, both measured in SI units, is 0.003 .

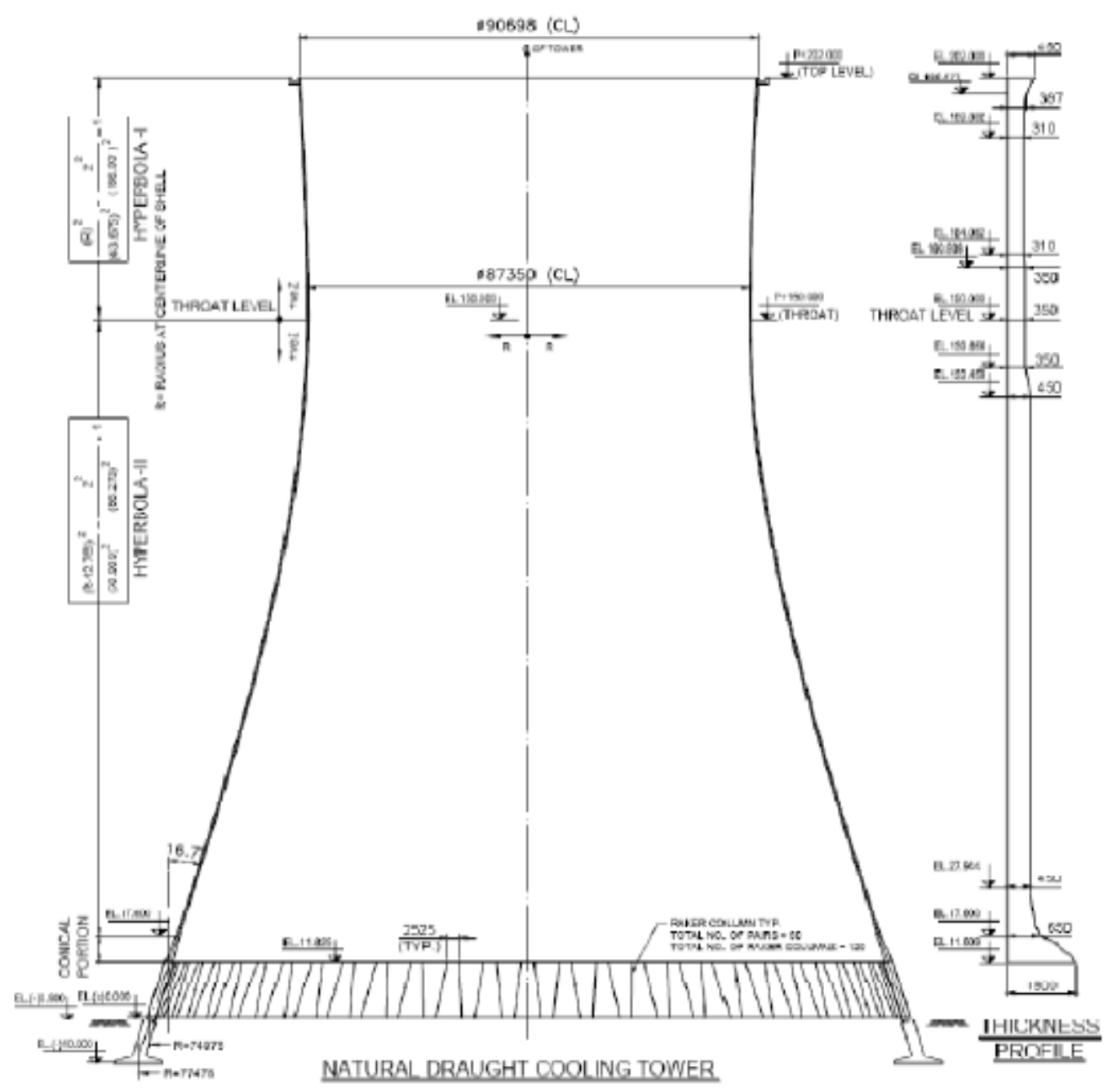

Fig 1 Dimensions of the Worlds Tallest NDCT at Kalisindh, Rajasthan 


\subsection{Choice of Shell Geometry and Shell Thickness}

This structure is the world's highest NDCT with total height of $202.0 \mathrm{~m}$ above FGL and basin diameter of $149.35 \mathrm{~m}$. For a given base diameter and height of the fill, height and throat diameter of the tower, the first step in deciding the shape of the cooling tower consists of choosing the geometrical shape of the meridian and arrive at the required thickness in an approximate way. In further detailed steps the wall thickness is varied over the height, taking buckling resistance into account and optimizing concrete quantities. Shell profile and thicknesses are optimized after many trials so that dead load and wind load are minimum. The code of practice is initially used at this stage, but is inadequate in many respects for the design of cooling tower. In particular, considerable effort was necessary to obtain realistic estimate of wind load. The task was difficult, since no reference is available for tower of $202 \mathrm{~m}$ height and subjected to high wind load. The shell thickness is decided based on two buckling criteria namely snap through buckling, as per IS: 11504-1985 and element local buckling criteria as per BS 4485-4:1996. The factor of safety against buckling is kept more than 5 as per codal requirement.

\subsection{Stiffening of Top Portion of NDCT}

Frequencies of different modes of vibration are studied. It is seen that first few modes of vibrations are circumferential. So top edge of the shell is required to be stiffened by integrating the walkway platform a part of the top channel.(fig,2) and thus provide the required stiffening.

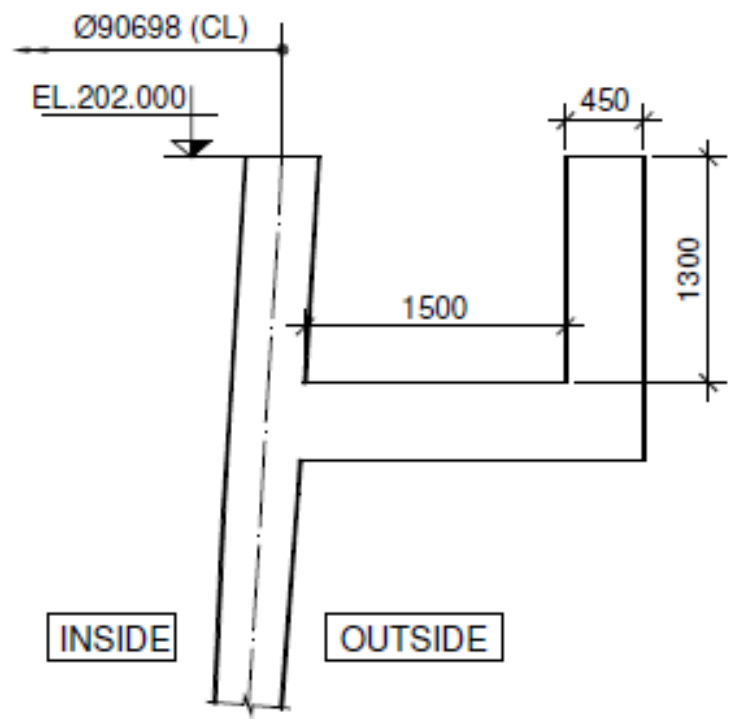

Fig 2 Details of Stiffened top portion of NDCT

\subsection{Raker Columns}

At the junction of the ring beam and the columns, the use of common tangent makes the flow of forces from shell to the columns smooth and avoids any secondary radial forces. The shape of raker columns is modified from rectangular to circular, which is useful for achieving smooth air flow between columns, resulting in efficient air draught. The reinforcement in circular columns is distributed more in the direction of predominant bending instead of uniform distribution. Thus gives optimum design. The variation of forces coming in the raker column due to wind load as per wind tunnel test is shown in the fig. 3 .

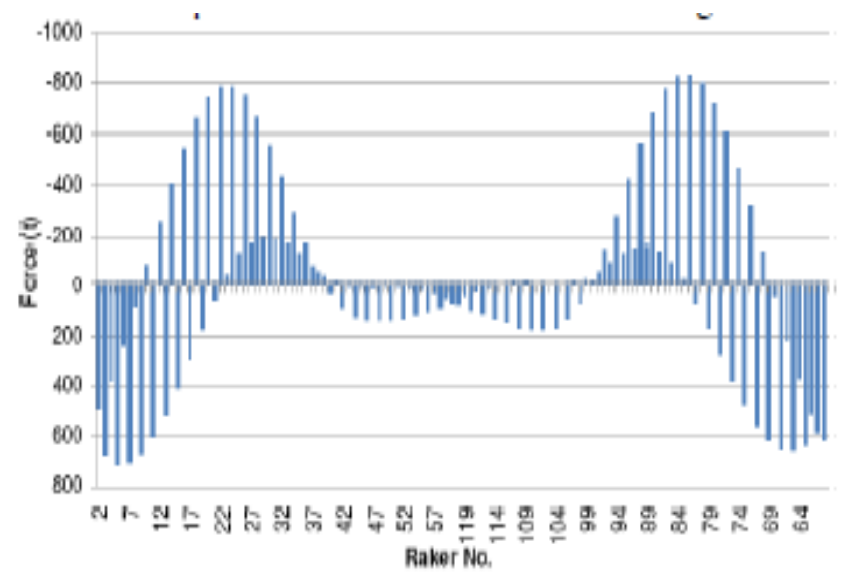

Fig 3 Forces in the raker column due to wind load as per wind tunnel test

\subsection{Tower Foundation}

Annular open RC foundation is provided below pedestal. The central portion of this annular foundation is designed as longitudinal beam with support at pedestal location. The overhang portion of annular foundation is designed as cantilever for underlying bearing pressure. Hoop reinforcement is provided to take care of hoop forces.

\section{STRUCTURAL MODELING AND ANALYSIS OF COOLING TOWER SHELL USING TWO DIFFERENT FINITE ELEMENT ANALYSIS SOFTWARES}

The NDCT is modeled and analysed by NISA (Numerically Integrated elements for System Analysis) for wind load cases; namely, the pressure diagram of IS code and the pressure diagram obtained from wind tunnel test on aeroelastic model of NDCT. The wind loading diagram obtained from the wind tunnel test was analysed using SAP 2000 software. The following statistics indicate enormity of the problem.

NISA:

1. Axisymmetric model of tower

2. Wind load application is as per IS code

3. Wind load application as per pressure obtained from wind tunnel test 


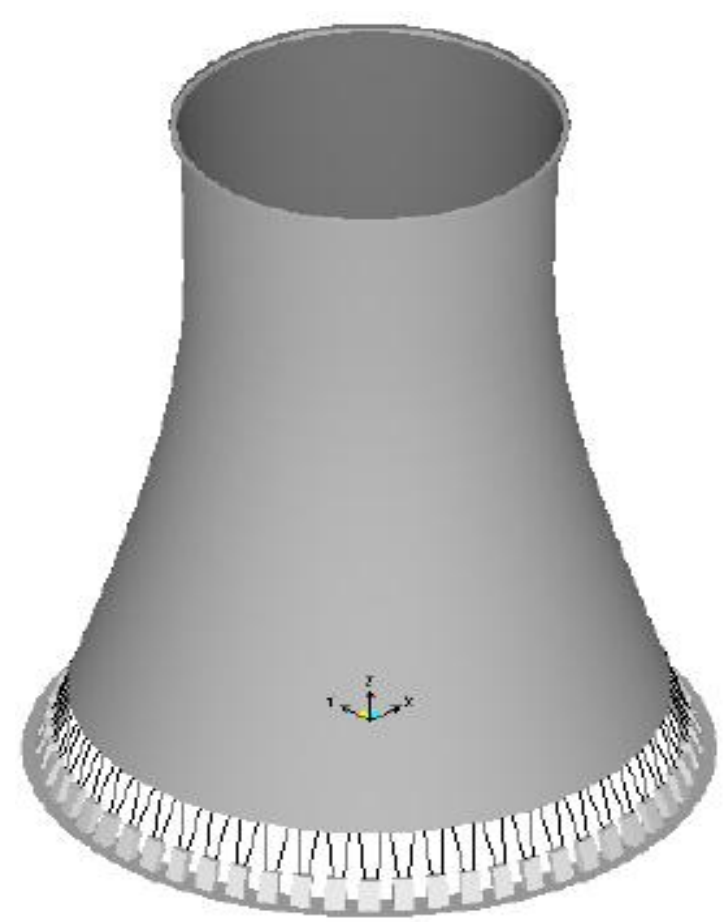

Fig 4 FEM model of tower shell

\begin{tabular}{|c|c|c|}
\hline Element & Element Type Used & Number \\
\hline Shell element & $\begin{array}{l}4 \text { nodded isoparametric } \\
\text { shell element }\end{array}$ & 18360 \\
\hline Raker & \multirow{3}{*}{ 3-D beam element } & 60 \\
\hline Pedestal & & 30 \\
\hline Foundation beam & & 240 \\
\hline Spring element & $\begin{array}{l}\text { Vertical, Radial and } \\
\text { circumferential torsional } \\
\text { spring }\end{array}$ & 723 \\
\hline $\begin{array}{l}\text { Total number of } \\
\text { nodes }\end{array}$ & & 19553 \\
\hline $\begin{array}{l}\text { Total number of } \\
\text { materials }\end{array}$ & & 4 \\
\hline
\end{tabular}

\section{SAP 2000:}

1. Full model of tower shell

2. Wind load applied by wind pressure obtained from wind tunnel test.

\begin{tabular}{|l|l|c|}
\hline Element & $\begin{array}{l}\text { Element Type } \\
\text { Used }\end{array}$ & Number \\
\hline Shell element & $\begin{array}{l}\text { 4 noded } \\
\text { isoparametric } \\
\text { shell element }\end{array}$ & 36720 \\
\cline { 3 - 3 } Foundation & 7200 \\
\hline Raker & Frame element & 120 \\
\hline Pedestal & $\begin{array}{l}\text { 3-D solid } \\
\text { element }\end{array}$ & 15360 \\
\hline $\begin{array}{l}\text { Spring } \\
\text { element }\end{array}$ & $\begin{array}{l}\text { General spring } \\
\text { element }\end{array}$ & 7920 \\
\hline $\begin{array}{l}\text { Total number } \\
\text { of nodes }\end{array}$ & & 66600 \\
\hline $\begin{array}{l}\text { Total number } \\
\text { of materials }\end{array}$ & & 4 \\
\hline
\end{tabular}



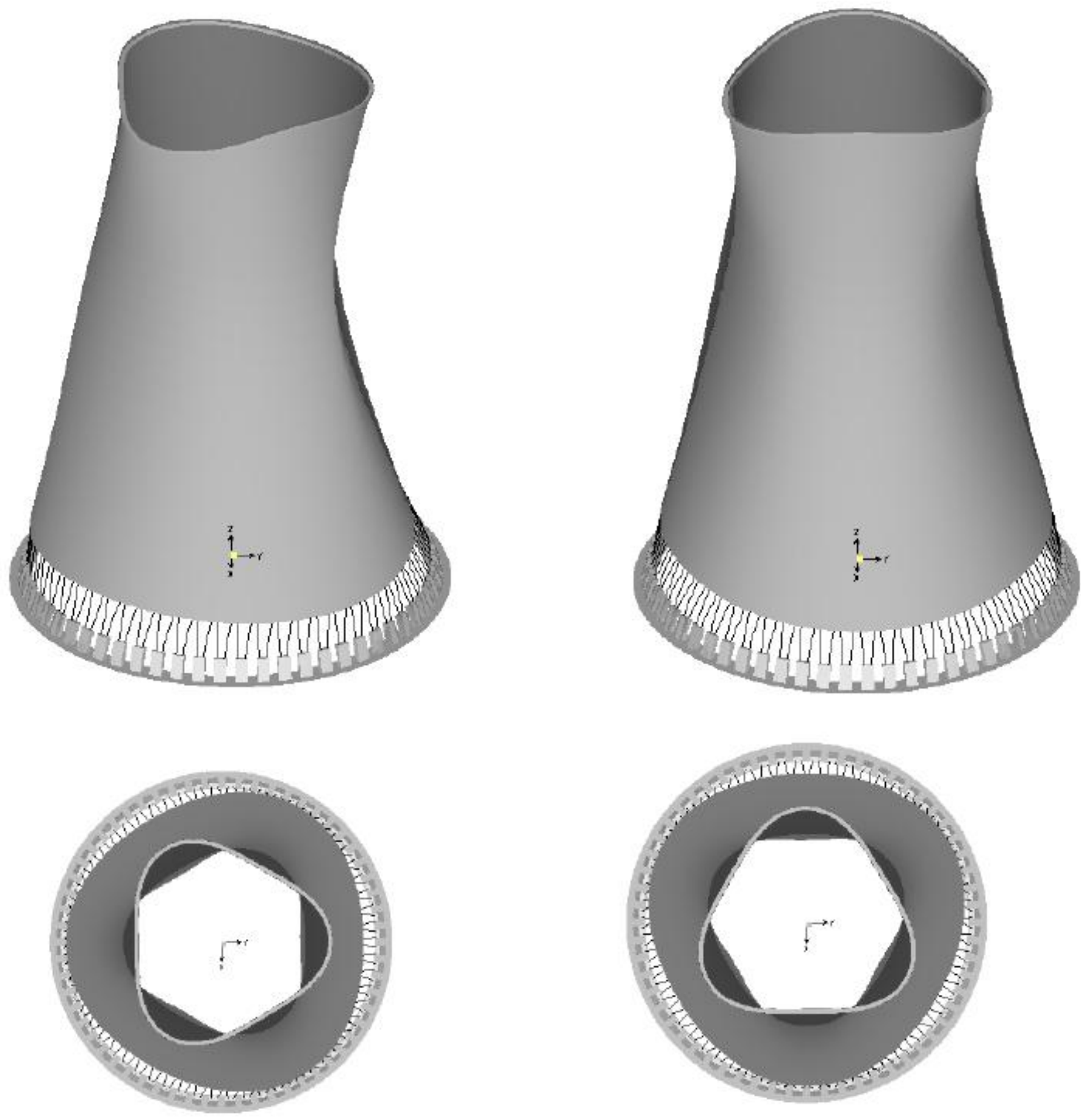

Fig 5 First 2 modes shapes of NDCT

\section{APPLICATION OF WIND PRESSURE OBTAINED FROM WIND TUNNEL TEST}

The height of NDCT demands determination of wind load to the state-of-the-art precision. So detailed wind tunnel study using 1:250 scale of aero- elastic model was made to establish the wind pressure for individual tower and for both towers together with adjacent tall structures. The test has given following results i.e. mean pressure coefficient ${ }^{-} C_{P}$ at every 150 interval circumferentially and for different height at 9 locations. All these values at different angle of incidents are multiplied by peak to mean pressure ratio " $n$ ". It is found that values of $\mathrm{C}_{\mathrm{P}} x n$ shows maximum results at $150^{\circ}$ and $180^{\circ}$ degree. Hence these two cases are used for pressure calculation. To establish the ${ }^{-} \mathrm{C}_{\mathrm{P}} x n$ at every degree along circumference and at different levels, firstly $\mathrm{C}_{\mathrm{P}} x n$ is obtained at each 10 degree interval by using spline curve interpolation method. Secondly $\bar{C}_{\mathrm{P}} x n$ obtained at each degree is linearly interpolated along height. Thus $\bar{C}_{\mathrm{P}} x n$ are established by using spline curve interpolation and linear interpolation. Further wind pressure is calculated at each node of tower shell by using following formula. 


$$
P=q \times n \times \overline{\mathrm{C}}_{\mathrm{P}}
$$

Where,

$\mathrm{q}=$ dynamic pressure

$\mathrm{n}=$ peak to mean pressure ratio

$\overline{\mathrm{C}}_{\mathrm{P}}=$ mean pressure coefficient obtained from wind tunnel test

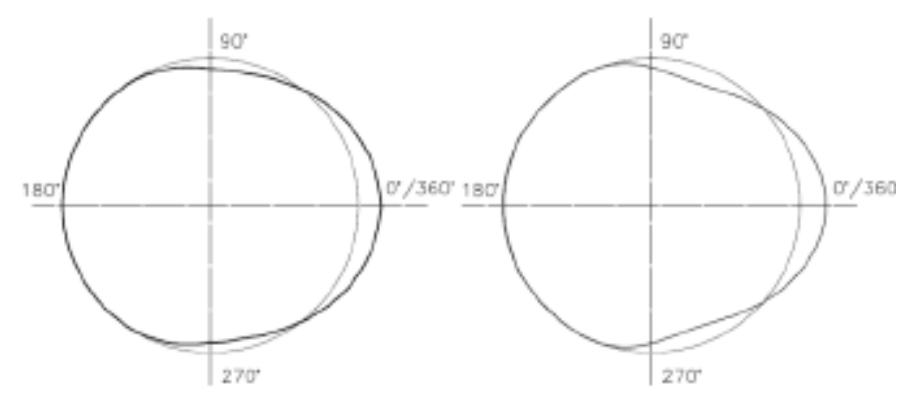

Fig 6 Wind load distribution as per Wind tunnel

Fig 7 Wind load distribution test as per IS code

\section{TOWER SHELL}

The bottom most conical portion of tower shell of total height $6 \mathrm{~m}$ is treated as ring beam. This portion of shell is heavily reinforced to transfer the total shell dead load properly to the raker column below. Reinforcement is provided in meridional and circumferential direction. Circumferential reinforcement is placed on outside, it will take care of hoop stress and moment develop due to wind load and dead load in circumferential direction. Medional reinforcement is provided on inner side taking care of dead load component and bending moment in meridional direction. Adequate cover is provided as there will be moist condition inside NDCT. The high strength concrete along with adequate cover is provided to ensure durability. Variation of axial force along the height of NDCT due to Dead load \& wind load is shown in fig 8 \& 9 respectively.
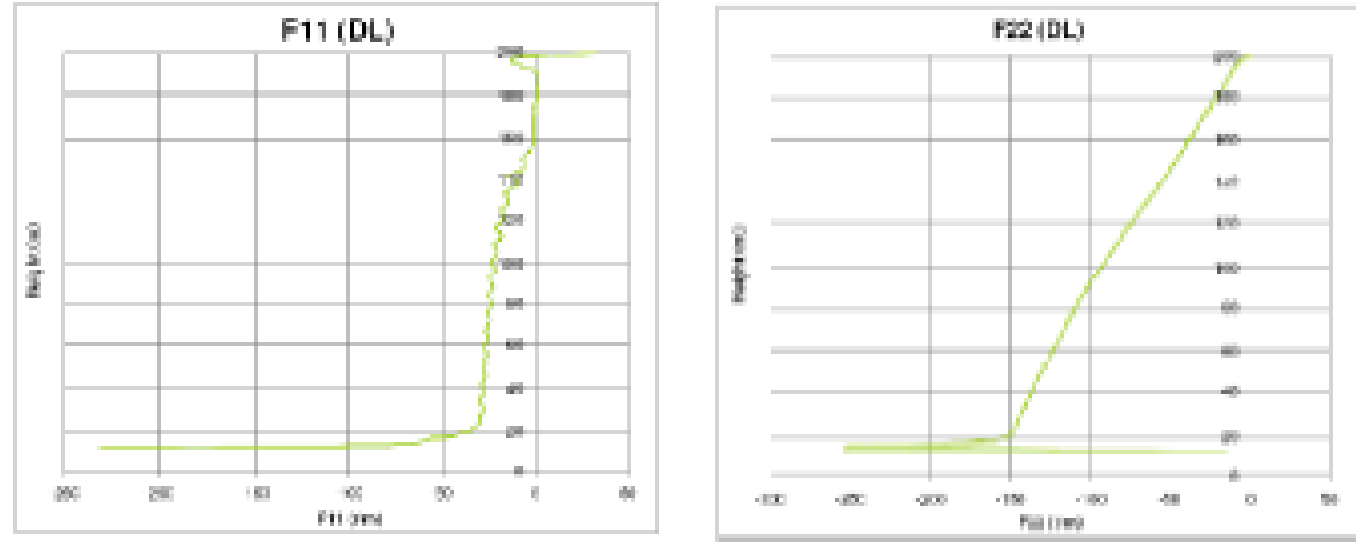

Fig 8 Variation of Axial forces along the height due to Dead load
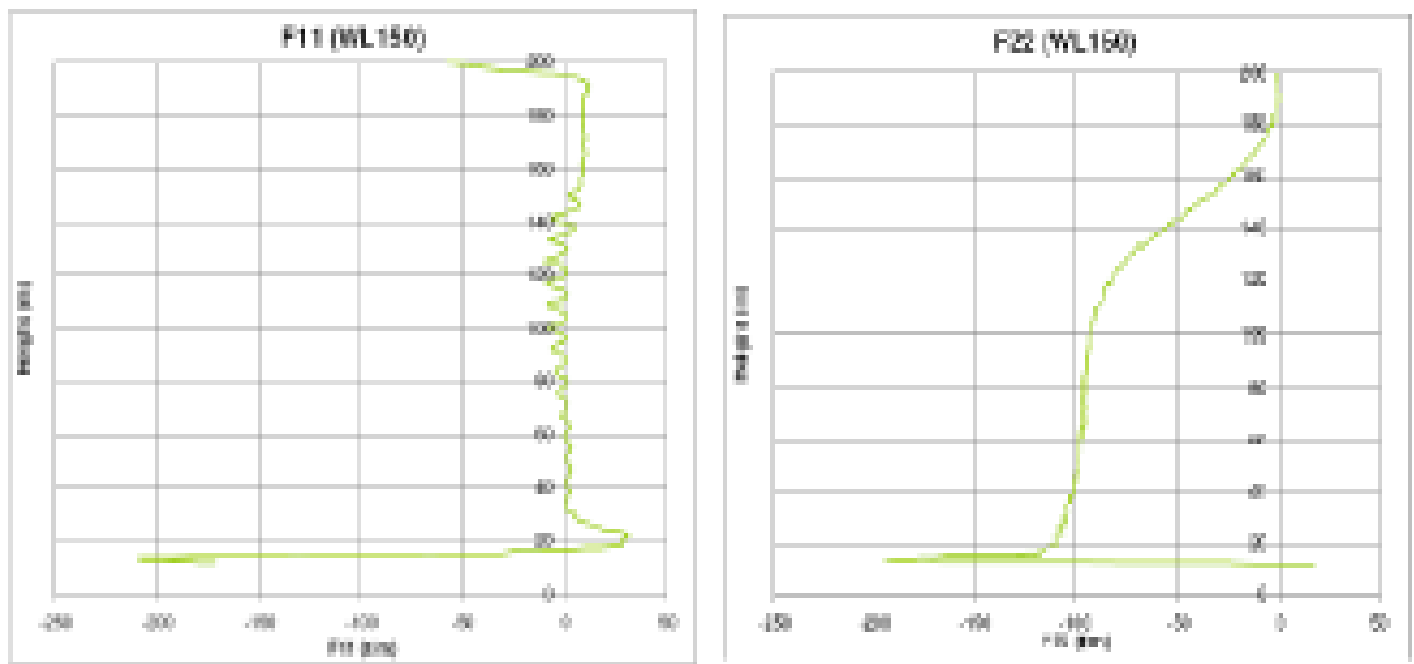

Fig 9 Variation of Axial forces along the height due to Wind load 


\section{MEASURES CONSIDERED FOR}

\section{DURABILITY OF SHELL}

Cooling tower shells are subjected to a relatively severe environment over their lifetime, which may span several decades. Hence, special care must be taken in order to provide a durable structure. While designing, minimum shell thickness of $310 \mathrm{~mm} \&$ concrete cover of $40 \mathrm{~mm}$ is considered. Also, the crack width is limited to $0.2 \mathrm{~mm}$. The opening in the shell for the inlet of hot water pipe is one of the point of concern for the durability of Shell. This concern is eliminated by avoiding the opening for hot water pipe in the shell \& providing hot water pipe passing between the raker columns.

\section{CONCLUSION}

Efficiency of power plant greatly depends upon proper functioning of cooling tower system (CWS) which plays a great role of minimizing requirement of water. Till date thermal designer has the restriction on sizing i.e. height and basin diameter of NDCT because there is no proven track record of large capacity NDCT. Now, with the successful design and construction of world's tallest NDCT having total $202 \mathrm{~m}$ height from FGL and basin diameter $149.35 \mathrm{~m}$ at Kalisindh TPP the new possibilities are open for thermal designers. Now they can design NDCTs with greater height and compact basin diameter. Also consulting engineering firms can come forward to design NDCTs of higher capacity as they now get a new benchmark. Also the number of required NDCTs can also be reduced.

\section{REFERENCES}

[1] IS:456-2000 -Plain and reinforced concrete - code of practice, Indian Standard

[2] IS:875(part 3)-1984, Code of practice for design loads (other than earthquake), part 3-wind loads, Indian Standard

[3] IS:11504:1985, Criteria for structural design of reinforced concrete natural draught cooling towers, Indian Standard

[4] BS:4485-4:1996, Code of practice for structural design and construction, British standard

[5] IIT Kanpur(2010), "Technical report on Wind tunnel study of NDCT for Kalisindh thermal power Project (2x600 MW)

[6] Part-1:Pressure measurement"

\section{BIOGRAPHIES}

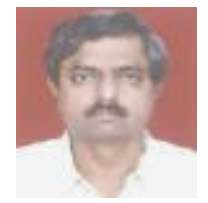

P.S. Patni, Joint Vice President, STUP Consultants Pvt. Ltd, in-charge of Design of Structures of Energy Group at Vashi, Navi Mumbai Office.

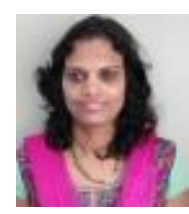

Jyoti D. Asrondkar, Senior Manager (Design), STUP Consultants Pvt. Ltd., designing of structures of Energy Group Vashi, Navi Mumbai Office. 